\title{
Development and validation of the disease - specific problems questionnaire for patients with multiple sclerosis
}

\author{
Ali Dehghani*
}

\begin{abstract}
Background: Patients with multiple sclerosis face numerous problems during their lifetime. A self-report measurement of disease - specific problems is required to be developed for patients with multiple sclerosis based on different cultural factors. Accordingly, this can advance our understanding on the disease-specific problems for care planning as well as improving coping ways and quality of life. This study aimed to develop and validate the scale of diseasespecific problems of Multiple Sclerosis.

Methods: This was an exploratory sequential mixed method study conducted in three phases. Correspondingly, in the first phase, the concept of disease-specific problems was defined using the content analysis approach in patients with MS. In the second phase, the item pool was generated from the findings of the first phase, and in the third phase, psychometric properties of the scale, including face, content, and construct validity and reliability, were evaluated.

Results: After examining both validity and reliability, 28 items were developed in the final questionnaire. As well, by performing the factor analysis, five factors were revealed as follows: physical problems, psychological problems, emotional problems, family problems, and socio-economic problems. Internal consistency and stability of the questionnaire were calculated as 0.82 and 0.90 , respectively, indicating an excellent reliability.
\end{abstract}

Conclusion: The 28-item questionnaire is valid and reliable for measurement of level of disease - specific problems in Iranian people with MS.

Keywords: Validation, Measurement, Global health, Questionnaire, Self-report, Multiple sclerosis

\section{Background}

Multiple sclerosis (MS) is a chronic inflammatory demyelinating disease leading to the development of progressive neurological disabilities [1]. It affects people aged between 20 and 40 years old. The prevalence of MS was estimated as 1.1 million worldwide [2]. According to the MS Society of Iran, the number of people with MS is reported as 78,890 cases [3].
MS is known as one of the most important lifechanging diseases because it damages the best periods of people's life and consequently leads to disability [4]. Symptoms and problems of MS, including fatigue, pain, spasm, weakness, visual impairment, imbalance, tremor, impotence, depression, and cognitive problems, are variable and unpredictable [5]. In addition, patients with MS mostly experience several physical and psychological problems affecting their daily activities, family and social life, independence, and individual planning for the future $[6,7]$.

Besides the problems experienced by patients with MS worldwide, Iranian patients mostly face additional 
problems in having access to medications, support for rehabilitation and medical costs, etc., all of which affect the management of disease and the patients' quality of life [8]. Some studies have previously investigated problems related to this disease in the patients; however, the majority of these studies have focused on only one aspect of these problems, including physical problems and using separate questionnaires for the same problem [9-11].

The main issue in this regard is that problems of these patients should be examined by a comprehensive, standardized, and native questionnaire. Those problems related to each dimension should also be identified using standard questionnaire, so that they can be effective on solving problems in these patients. Forbes et al. [12] in their study have developed a questionnaire to measure health-related quality of life in people with MS. In their study, the focus was only on assessing physical problems by a researcher-made questionnaire consisting of some items, including fatigue, pain, urinary-intestinal incontinence, depression, pressure ulcer, sexual problems, and employment. Indeed, no separate questions exist in this questionnaire regarding other problems in patients with MS like their family problems. Moreover, these questionnaires are used in different communities and cultures without considering any cross-cultural issue [13].

As anther similar questionnaire, measure of HRQoL was developed to assess physical, psychological, and social effects of health conditions on the individuals' well-being. Accordingly, this questionnaire is a general tool used to differentiate between disease-specific and general conditions [14]. Although some general measures like HRQoL may capture different elements of quality of life in patients, they consist of some domains that could be in different contexts rather than being specific to a condition [15]. As well, in this field, another commonly used questionnaire is the MSQOL-54, which mainly examines physical-psychological problems and does not include the problems attributed to patients with MS in different dimensions such as family and economic problems [16]. General Health Questionnaire (GHQ28 ) is also used to detect psychiatric disorders in medical practice, which has been previously validated for use among individuals with neurological disorders [17]. The Guy's Neurological Disability Scale (GNDS) comprises 12 symptom areas related to MS such as mood, mental, bladder, and bowel [18]. The above-mentioned questionnaires mainly examine the physical and psychological problems of patients with neurological disorders. On the other hand, in the development of these questionnaires, all stages of the psychometric properties of the questionnaire have not been completed and the items of the questionnaire have also been extracted from literature review. Indeed, no specific questionnaire has been developed for the measurement of disease-specific problems in patients with MS so far.

The present study aimed to develop a valid and reliable questionnaire to assess the level of disease-specific problems in patients with MS, namely MS disease-specific Problems Questionnaire (MSPQ). Since the assessment of disease-specific problems in patients with MS can provide appropriate information regarding problem identification and making future decisions in some fields such as education, interventions, reformation, and improvement. On the other hand, the developed questionnaire must be adapted to socio-cultural context of Iran. Therefore, this study was conducted with these objectives.

\section{Materials and methods}

\section{Study design and participants}

This was an exploratory sequential mixed method study that was conducted in three phases and two sections of qualitative and quantitative. An exploratory sequential mixed method study includes the following steps [19]:

1) Defining the concepts

2) Formulating the items of the questionnaire

3) Developing the questionnaire

4) Testing validity and reliability of the questionnaire

Data were collected from February 2019 to December 2020 at the MS Society in Jahrom, Iran. The study was conducted in three phases as the following (Fig. 1).

\section{The first phase}

In this phase, the concept of disease-specific problems in patients with MS was conceptualized and then defined using the conventional content analysis. Using this method, some codes and classifications were directly extracted from the interviews with patients. Through the content analysis, the findings are interpreted by translating data in words and putting in some themes, involving some areas, including understanding, interpreting, and conceptualizing of underlying meanings of the qualitative data [20].

At this stage, 15 patients with MS were enrolled in the study. The required data were collected from the participants using semi - structured and individual interviews. The inclusion criteria were the followings: (1) definite diagnosis of MS, (2) willingness to participate in the study, (3) ability to express their experiences, and (4) at least two years past from MS diagnosis. Of note, the patients at the exacerbation stage were excluded from the study. Each interview lasted on average $45-60 \mathrm{~min}$, and these interviews were conducted in the MS Society in Jahrom based on the participants' prior agreement regarding the comfortable time. The interviews with the patients continued 


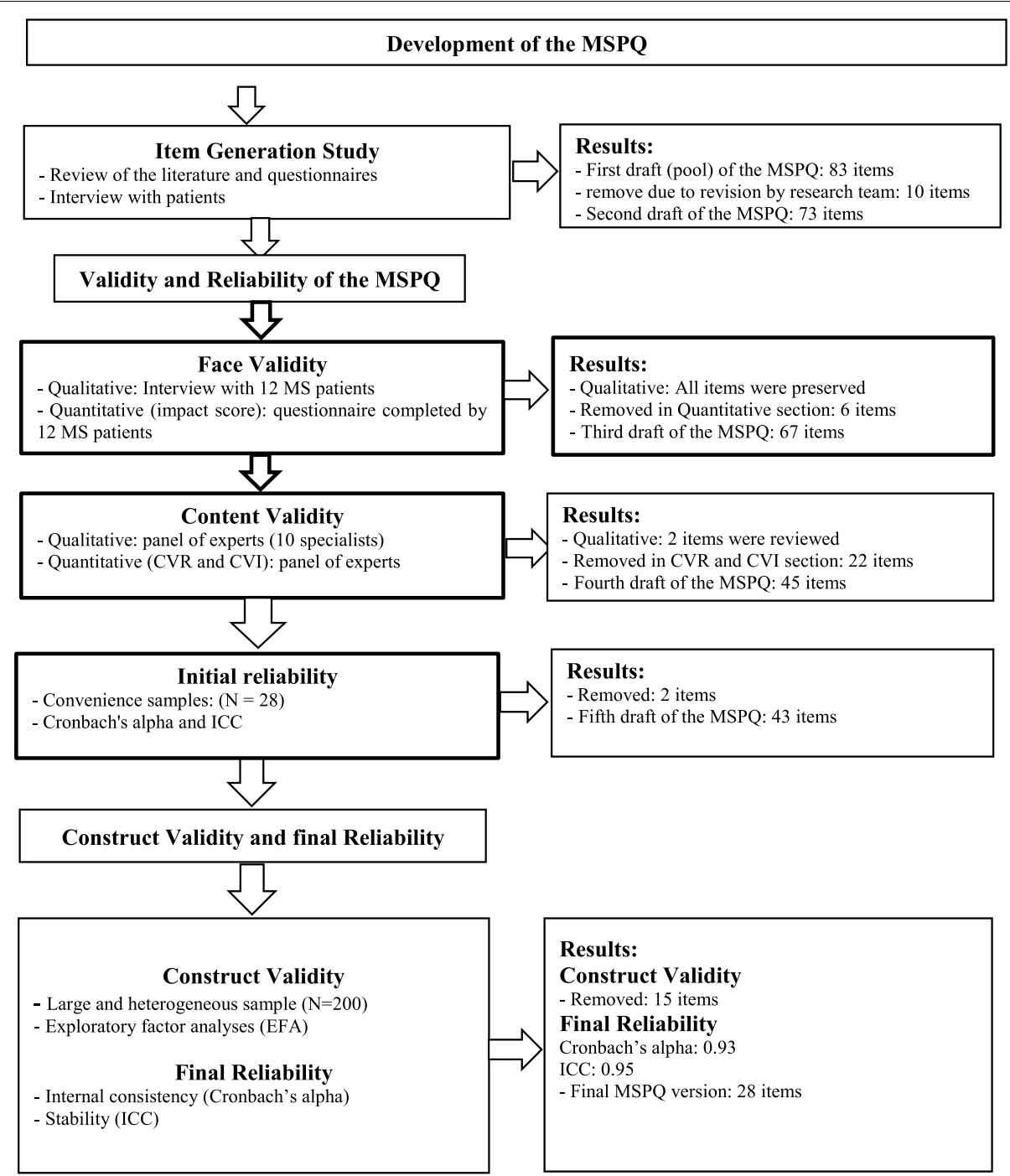

Fig. 1 Flow diagram of the development and validation of the disease - specific problems Questionnaire in MS patients (MSPQ)

up to reaching data saturation. Moreover, these interviews were audio-recorded, then transcribed verbatim in MAXQDA software, Ver10 to manage coding process. Thereafter, the obtained data were analyzed using the conventional content analysis developed by the Graneheim and Lundman model [21]. Furthermore, at this stage, the initial codes were extracted, and subcategories and categories were then formed. Finally, dimensions of disease-specific problems were extracted and their concept was defined in patients with MS.

\section{The second phase}

In this phase, the items pool was formed to develop a disease - specific problems questionnaire for patients with MS based on the following steps:
1. Dimensions extracted from the first phase of the study for disease - specific problems

2. Reviewing relevant texts in the field of disease - specific problems

3. Reviewing relevant problems questionnaires

\section{The third phase}

In this phase, psychometric properties, including face, content, and construct validity, and reliability of the items pool, were examined in order to develop the questionnaire. These properties were as follows:

A) Face validity: The face validity was examined in two qualitative and quantitative sections. Accordingly, the 
qualitative section was conducted by holding individual interviews with 12 patients with MS. During these sessions, these patients were asked about the difficulty, relevancy, and ambiguity of the items, and then the questionnaire was revised based on their recommendations. For the quantitative part, these 12 patients were requested to evaluate the questionnaire and the rank each item based on its importance on a 5 -point Liker scale in order to calculate 'Item Impact Score' (Impact Score $=$ Frequency $(\%) \times$ Importance). Finally, the impact score of 1.5 or above was considered as satisfactory [22].

B) Content validity: same as previous, content validity was evaluated in two qualitative and quantitative sections. In the qualitative part, 12 experts were asked to assess the questionnaire about its grammar, clarity of items, placement of items, and accurate scoring system [23]. In the quantitative part, both content validity ratio (CVR) and content validity index (CVI) were calculated for each one of the items of the questionnaire. The CVR of each item was then evaluated on a 3-point scale, including essential, useful, but not essential by 10 experts, based on Lawshe [24] and the modified table by Ayre and John Scally [25]. Of note, CVR varies between 1 and -1 , in a way that a higher score indicates greater agreement among panel members. Given the number of 12 experts, the items with the CVR value of 0.80 and higher were maintained. Formula of CVR is as follows: $C V R=(\mathrm{Ne}-\mathrm{N} / 2)$ / $(\mathrm{N} / 2)$, where $\mathrm{Ne}$ is the number of panelists indicating an item as "essential" and $\mathrm{N}$ is the total number of panelists [26]. Using the CVI, the relevance of each item was analyzed by 10 experts on a 4-point Likert scale (scored as not relevant: 1; a little relevant: 2; somewhat relevant: 3 ; and extremely relevant: 4) [26]. The CVI was computed as the number of the experts giving a rating item 3 or 4 for each item divided by the total number of the experts. Values ranged from 0 to 1 , and when $C V I>0.79$, the item was relevant, between 0.70 and 0.79 , the item needed revisions, and if the value was below 0.70 , the item was eliminated [27].

C) Initial reliability: In this part, correlations between items and the questionnaire were calculated using Cronbach's alpha and inter-item correlation coefficient (ICC).

D) Construct validity: in this part, the exploratory factor analysis (EFA) was used to determine construct validity of the MSPQ. Correspondingly, the EFA was used to determine any interrelationship between items and also to summarize the related items in a dimension [28]. In the EFA, by applying the principal axis factoring (PAF) for factors' extraction, Kaiser-
Meyer- Olkin index (KMO) was used to determine the sampling adequacy. Thereafter, Bartlett's Test was used for the evaluation of correlation between the items of the questionnaire in order to integrate them and oblique rotation for simplifying and interpreting the factor structure through taking the eigenvalues greater than 1 . The number of the participants required for performing factor analysis per each item is between 3 and 10 people [29]. The questionnaire was completed by 200 patients with MS who were selected through convenience sampling (Table 1). In this regard, Factor loadings more than 0.3 were considered as appropriate [30].

After factor analysis, the known-groups comparison was used for evaluating the test's ability to discriminate between groups based on different mean scores on the test [31]. The known groups in this study were groups of MS patients with different educational levels. Thus, score of disease - specific problems was measured and compared using one-way analysis of variance one way ANOVA test in three groups of education. The convergent validity was also used for correlation between the results of two questionnaires measuring the same variable that are theoretically related [32]. The Persian version of the General Health Questionnaire (GHQ-28) [17] was employed to assess the convergent validity of the MSPQ. Thus, 200 MS patients were concurrently completed both the Persian version of the General Health Questionnaire (GHQ-28) and the MSPQ. Then, the correlation between scores of the two scales was compared using Pearson test.

E) Final reliability: Reliability of the MSPQ was determined through internal consistency and stability

Table 1 Demographic characteristics of the samples in EFA section $(N=200)$

\begin{tabular}{lll}
\hline variables & & $\mathbf{N}(\%)$ \\
\hline Age (years) & Mean \pm SD & $36.12 \pm 9.11$ \\
Duration of MS (years) & Mean \pm SD & $11.22 \pm 4.31$ \\
Gender & male & $75(37.5)$ \\
& female & $125(62.5)$ \\
Educational status & Under diploma & $42(21)$ \\
& diploma & $(30) 60$ \\
Number of recurring during the & Upper diploma & $98(49)$ \\
past year & No recurring & $128(64)$ \\
& once & $40(20)$ \\
Expanded Disability Status Scale & More than two times & $32(16)$ \\
(EDSS) & 2-1.5 & $145(72.5)$ \\
& 4-5.5 & $52(26)$ \\
\end{tabular}


methods. For determinate the internal consistency, the MSPQ was completed by 20 MS patients and then Cronbach's alpha coefficient was calculated. Alpha coefficient above 0.7 was considered as appropriate for the reliability [33]. In order to evaluate the stability of the MSPQ, a test-retest method was conducted. The MSPQ were completed by $20 \mathrm{MS}$ patients at two time stages with on 2-week intervals [34]. Then, the correlation of scores between the two tests was determined with ICC. The ICC above 0.8 represents the optimal stability of the questionnaire [35].

\section{Statistical analysis}

Statistical analyses were conducted using the SPSS version 20.0. Normality of data was confirmed through Kolmogorov-Smirnov test. Descriptive analysis, factor analysis, EFA, PAF, KMO, Bartlett's Test, Cronbach's alpha, ICC and Pearson test were used for data analysis.

\section{Results}

The results of the study are presented in three phases.

\section{The first phase}

In this phase, the concept of disease-specific problems was defined in patients with MS based on the literature review as well as the patients' experiences using the conventional content analysis. The disease-specific problems in patients with MS are considered as a dynamic, complex, and multidimensional concept with different dimensions. Accordingly, the dimensions of diseasespecific problems among MS patients include physical problems, psychological problems, emotional problems, family problems, and socio-economic problems.

\section{The second phase}

In this phase, findings obtained from the literature review and the qualitative content analysis were employed to generate an item pool for the MSPQ scale. The item pool consists of 83 items categorized into five aspects of physical, psychological, emotional, family, and socio - economic problems. Afterward, the research team reviewed the items of the MSPQ scale to assess overlapping items, and as a result, 10 items were removed from the questionnaire and 73 items remained at last.

\section{The third phase \\ Face validity}

In the qualitative part of the face validity, three items were modified the patients' recommendations. Moreover, in the qualitative part of the face validity, six items were deleted due to an impact item score lower than 1.5. Therefore, 67 items finally remained in the MSPQ scale.

\section{Content validity}

In the qualitative part, two items were modified according to the expert panel comments. Using CVR analysis, 19 items were deleted because of obtaining CVR value lower than 0.80 . In addition, three items were removed because of CVI value lower than 0.79. At last, 45 items remained in the MSPQ scale.

\section{The initial reliability}

The internal consistency of the MSPQ was obtained as 0.94 using Cronbach's alpha. The correlation between items No. 13 "MS makes me to become very tired" and the whole MSPQ was 0.03 , and between item No. 5 "I have spasms and muscle cramps caused by the disease", it was obtained as -0.025 . Therefore, these two items were removed due to having a correlation lower than 0.3 . Eventually, 43 items remained in the MSPQ scale.

\section{Construct validity}

In this part, $200 \mathrm{MS}$ patients included from the MS Society of Jahrom completed the 43-item MSPQ scale. The Kaiser-Meyer-Olkin (KMO) and Bartlett's test were employed, which illustrated that the obtained data were proper for factor analysis (KMO index $=0.921$, $\left.X^{2}=5432.322, P<0.001\right)$. The EFA with PAF as well as oblique rotation led to the extraction of five factors with eigenvalues greater than 1 . An oblique rotation identified five latent factors, and in this regard, Table 2 shows the eigenvalues, percentage of variance for five factors, and factor loadings for the items that met the retention criteria. Therefore, 15 items were deleted from the MSPQ scale because of having factor loading lower than 0.3. Finally, 28 items and five factors remained in the MSPQ scale. Accordingly, these five factors of the MSPQ scale were as follows: factor one: "physical problems" with 9 items; factor two: "psychological problems" with 5 items; factor three: "emotional problems" with 4 items; factor four: "family problems" with 3 items; and factor five: "socio - economic problems" with 7 items. The five rotated factors explained $58.75 \%$ of the total variance. Of note, an additional file shows the developed questionnaire for this study with more details [see supplementary file].

Thereafter, the items of the MSPQ were rated on a fivepoint Likert-type scale from 1 to $5,1=$ never, $2=$ rarely, $3=$ sometimes, $4=$ often, and $5=$ always.

In order to assessment discriminating of the MSPQ in known-groups comparison was used from educational levels. Based on some researches [36, 37], MS patients with lower educational level have more problems. In 
Table 2 Factors, items and factor loadings of The MS disease - specific Problems Questionnaire (MSPQ -28$)^{*}(n=200)$

\begin{tabular}{|c|c|c|c|c|c|c|}
\hline \multirow[t]{2}{*}{ subscales } & \multirow[t]{2}{*}{ Item } & \multicolumn{5}{|l|}{ Factors } \\
\hline & & 1 & 2 & 3 & 4 & 5 \\
\hline \multirow[t]{9}{*}{ Physical problems } & $\begin{array}{l}\text { I have trouble doing daily ordinary activities (bathing, wearing own clothes, } \\
\text { etc.) }\end{array}$ & 0.802 & 0.301 & 0.002 & 0.162 & 0.293 \\
\hline & I have physical pain & 0.775 & 0.322 & 0.351 & $0.123-$ & 0.220 \\
\hline & I have general weakness and lethargy & 0.880 & 0.201 & 0.143 & 0.432 & 0.012 \\
\hline & I have visual impairment like double vision, etc. & 0.579 & 0.250 & 0.298 & 0.004 & 0.198 \\
\hline & I have an imbalance like loss of control of body movements & 0.798 & $0.002-$ & 0.005 & 0.321 & 0.213 \\
\hline & I have urinary and bowel incontinence & 0.467 & 0.178 & $0.009-$ & 0.245 & 0.001 \\
\hline & I have insomnia & 0.689 & 0.234 & 0.432 & 0.006 & 0.015 \\
\hline & I have memory disorder and forgetfulness & 0.588 & 0.098 & 0.265 & 0.007 & 0.087 \\
\hline & I have tingling and numbness in the hand and leg & 0.856 & 0.201 & 0.345 & 0.256 & 0.005 \\
\hline \multirow[t]{5}{*}{ Psychological problems } & $\begin{array}{l}\text { The disease has caused negative feelings such as sadness, depression, and } \\
\text { anxiety }\end{array}$ & & 0.876 & 0.201 & 0.444 & 0.093 \\
\hline & I feel distressed and confused & 0.001 & 0.895 & 0.210 & 0.355 & $0.002-$ \\
\hline & I feel feared without justified reason & 0.187 & 0.789 & 0.421 & 0.220 & 0.045 \\
\hline & I feel consuming a lot of mental energy & 0.002 & 0.880 & 0.012 & 0.002 & 0.056 \\
\hline & I feel dissatisfied toward my body style & $0.054-$ & 0.351 & 0.007 & 0.156 & 0.043 \\
\hline \multirow[t]{4}{*}{ Emotional problems } & The disease makes sensitive and irritable & 0.321 & 0.098 & 0.885 & 0.234 & 0.002 \\
\hline & $\begin{array}{l}\text { The disease has made more introverted and indifferent toward surrounding } \\
\text { issues }\end{array}$ & 0.067 & -0.045 & 0.882 & 0.123 & 0.034 \\
\hline & $\begin{array}{l}\text { The disease has led to a decline in my emotional relationships with my } \\
\text { spouse and family members }\end{array}$ & 0.250 & 0.231 & 0.898 & 0.345 & 0.423 \\
\hline & I can't handle my negative emotions & 0.001 & 0.042 & 0.499 & 0.211 & 0.001 \\
\hline \multirow[t]{3}{*}{ Family problems } & The disease has reduced my relationship with family members & 0.122 & 0.324 & 0.432 & 0.885 & \\
\hline & The disease has reduced my role and function in the family & 0.088 & -0.002 & 0.044 & 0.876 & \\
\hline & The disease has caused problems in my matrimony and sexuality & 0.145 & 0.222 & 0.033 & 0.589 & \\
\hline \multirow[t]{7}{*}{ Socio-economic problems } & The disease has caused problems in my job & 0.542 & $0.057-$ & 0.234 & 0.001 & 0.888 \\
\hline & The disease has reduced my social relationships with others & 0.213 & 0.245 & 0.215 & 0.176 & 0.880 \\
\hline & The disease has reduced my ability and function in the community & 0.287 & $0.001-$ & 0.178 & 0.087 & 0.689 \\
\hline & I have trouble doing social activities (attending in ceremonies, etc.) & 0.287 & $0.001-$ & 0.321 & 0.098 & 0.497 \\
\hline & I suffer from perspective of community toward MS disease & 0.213 & 0.321 & 0.002 & $0.045-$ & 0.870 \\
\hline & I have trouble in providing my medication and medical treatment & 0.123 & 0.211 & 0.321 & 0.045 & 0.492 \\
\hline & $\begin{array}{l}\text { The lack of socio-economic supports (financial, educational, supportive, } \\
\text { services, etc.) led to problems for me. }\end{array}$ & 0.159 & $0.054-$ & 0.301 & 0.034 & 0.850 \\
\hline Eigenvalue & & 9.250 & 7.450 & 5.43 & 3.38 & 1.894 \\
\hline Percentage of variance & & 21.219 & 17.456 & 12.232 & 5.132 & 2.711 \\
\hline
\end{tabular}

the present study, patient's educational level was classified in three levels including under diploma, diploma and upper diploma. The results of one way ANOVA showed a significant difference between groups $(P$ value $=0.001)$. The results of Turkey's post-hoc test showed disease - specific problems higher is in patients with under diploma educational level than other two groups. The result of correlation between the MSPQ and the Persian version of the General Health Questionnaire (GHQ-28) with Pearson test was 0.561 ( $P$ value $<0.001)$, which represents optimal convergent validity.

\section{Final reliability}

Cronbach's alpha for the 28-item MSPQ scale was 0.82 , which showed optimal internal consistency. The ICC between test and retest measurements was 0.90, which indicated an acceptable stability of the MSPQ scale over the time. Cronbach's alpha and ICC were determined for five factors that are shown in Table 3. For stability through test-retest analysis, Spearman's correlation coefficient was reported 0.87 . 


\section{Discussion}

The present study attempted to develop and validate a scale for disease-specific problems in patients with MS. Furthermore, since the objective measure ofthe diseasespecific problems do not appear to capture the patient's experiences completely, self-reports were employed in this study. The result show that the MSPQ scale is a reliable and valid instrument for the evaluation of the disease-specific problems. Our approach to create a new instrument was multifaceted and iterative using both qualitative and quantitative methods in its development. Since no instrument has been designed in Iran so far to evaluate the disease-specific problems and to evaluate the feedback to health personnel in a semi-structured model of problems identification and care planning, it was crucial to develop and validate an instrument used to evaluate the important dimensions of the disease-specific problems and to provide an opportunity for giving feedback to health personnel.

Different studies have previously used various questionnaires to assess the problems of patients with MS such as the measurement of fatigue using FSS scale [38]; stress, anxiety, and depression using DSAA 21 scale [39]; and physical problems using several questionnaires $[12,40,41]$. It was indicated that the MSPQ scale could be used to evaluate all the disease-specific problems, including physical, psychological, emotional, family, and socio - economic problems in patients with MS in a single questionnaire. In fact, it was attempted to eliminate weaknesses of other instruments in this instrument. The advantages of an overall MSPQ scale are as follows: it gives a holistic picture, as well as information on the impact of MS disease on patients. As an example, Forbes et al. [12] have introduced an instrument regarding health problems, which has been repeatedly used in various studies, but it does not evaluate some areas of the disease-specific problems such as emotional, family, and socio - economic problems, so it cannot be used for those MS patients with multidimensional problems. Besides physical problems, many people with MS experience some other problems, including the history of disorders in family and social relationships, dysfunction, social role, and occupational problems, which require attention and consideration [6]. Patients with MS mostly experience several difficulties in emotion regulation, psychological condition, and providing medical costs that predict poorer quality of life. These findings indicate that emotional and psychological outcomes controlling skills should be investigated with more details when considering interventions to enhance well-being among MS patients [42]. As well, patients with MS experience more difficulties in emotion and psychological conditions' regulation compared to healthy people. Mediation analyses indicated that depression could mediate the emotion regulation difficulties during MS course. Therefore, difficulties in emotion regulation could help in predicting poorer psychological and social quality of life in MS patients [43].

In the present study, a positive significant correlation was found among the number of recurrences during the past year, Expanded Disability Status Scale (EDSS), and the dimension of the MSPQ. Based on results of the study by Nortvedt et al., the correlation between the sexual summary scale and EDSS was calculated as 0.24 [10]. Correspondingly, these findings are consistent with the results of studies by Pike et al. [1] and Dehghani et al. [44]. In addition, a negative significant correlation was observed among the duration of MS (years), educational level, and the dimension of the MSPQ. In consistent with these results, the findings of Simeoni et al's study showed that the MusiQoL dimension scores were significantly higher for patients with a greater educational level compared to those having a moderate or low educational level [36].

One of the strengths of this study was that the MSPQ was developed using both inductive and deductive methods. Its psychometrics properties have also been examined through face, content, and construct validity, as well as reliability (internal consistency and stability). The MSPQ is a 28 -item short questionnaire that

Table 3 Descriptive statistics and reliability measurements of the MSPQ -28

\begin{tabular}{|c|c|c|c|c|c|c|}
\hline Factors & Subscales & $\begin{array}{l}\text { Number of } \\
\text { items }\end{array}$ & Cronbach's Alpha & ICC (95\% CI) & $\begin{array}{l}\text { Spearman's Correlation } \\
\text { Coefficient }(n=20)\end{array}$ & $p$-Value \\
\hline 1 & Physical problems & 9 & $a=0.74$ & $\mathrm{ICC}=0.81$ & 0.89 & 0.001 \\
\hline 2 & Psychological problems & 5 & $a=0.77$ & $\mathrm{ICC}=0.87$ & 0.91 & 0.001 \\
\hline 3 & Emotional problems & 4 & $a=0.80$ & $\mathrm{ICC}=0.91$ & 0.85 & 0.001 \\
\hline 4 & Family problems & 3 & $a=0.79$ & $\mathrm{ICC}=0.88$ & 0.82 & 0.001 \\
\hline \multirow[t]{2}{*}{5} & Socio-economic problems & 7 & $a=0.74$ & $\mathrm{ICC}=0.85$ & 0.92 & 0.001 \\
\hline & MSPQ & 28 & $a=0.82$ & $I C C=0.90$ & 0.87 & 0.001 \\
\hline
\end{tabular}


can be responded by patients with MS in a short time (10-15 min). The greatest strengths of this study were the design and development of a context-based health condition, in order to assess Iranian MS patients' disease-specific problems.

The lengthy and ongoing processes in the development, validation, and evolution of a new questionnaire as well as suffering scale of self-report were the current study's limitations. Another limitation was that it was not possible to gather objective data on the patients' disability levels, which may be known as a mediating factor in the disease-specific problems of patients. Another important limitation of the study was the lack of measures derived from already validated questionnaires to investigate the concurrent/divergent validity of the new developed questionnaire.

\section{Conclusion}

In this study, the five-dimension MSPQ was developed as a short self-report scale for measurement of disease specific problems in Iranian people with MS. The MSPQ is a valid, reliable and context-based scale, which can be used in education, research, care management, needs assessment, and support services.

\begin{abstract}
Abbreviations
MS: Multiple sclerosis; HRQoL: Health-related quality of life; MSQOL-54: Multiple sclerosis quality of life; MSPQ: Multiple Sclerosis disease - specific Problems Questionnaire; one way ANOVA: One-way analysis of variance; ICC: Intraclass correlation coefficient; PAF: Principal axis factoring; KMO: Kaiser- meyer- olkin; CVR: Content validity ratio; CVI: Content validity index; EFA: Exploratory factor analyses; MusiQoL: Multiple Sclerosis (MS) International Quality of Life.
\end{abstract}

\section{Supplementary Information}

The online version contains supplementary material available at https://doi. org/10.1186/s12883-021-02442-y.

Additional file 1. The disease - specific problems Questionnaire in Multiple Sclerosis Patients. In this section, a number of 28 items developed questionnaire to assess disease - specific problems in MS patients are listed in a table.

\section{Acknowledgements}

We thank gratefully all MS patients who participated in this research. Also, from experts and individuals who contributed to the validity and reliability of the questionnaire in this study are appreciated.

\section{Author's contributions}

AD contributed to the study conception and design. Material preparation, data collection and analysis was performed by AD. The first draft of the manuscript was written by $A D$. AD read and approved the final manuscript.

\section{Funding}

This work was supported by the Research Department at Jahrom University of Medical Sciences for research project. The funding bodies did not have any influence on the study design or on data collection, analysis, and interpretation of data or on writing the manuscript.

\section{Availability of data and materials}

All data generated or analyzed during this study are included in this published article. Further data set could be obtained on request if required through corresponding author with email: ali.dehghani2000@gmail.com.

\section{Declarations}

\section{Ethics approval and consent to participate}

This study was approved by the ethics committee of Jahrom University of Medical Sciences (Code of Ethics IR. Jums. Rec.1397.041). We followed the guidelines outlined in the Declaration of Helsinki and patients received information, both written and verbal, stating that completing the questionnaire was voluntary, anonymous, and that study results would be published. Consent to participate was obtained from each patient. Written informed consent was obtained from all patients.

\section{Consent for publication}

Not Applicable.

\section{Competing interests}

None of the authors have any conflicts of interest to disclose.

Received: 19 July 2021 Accepted: 18 October 2021

Published online: 27 October 2021

\section{References}

1. Pike J, Jones E, Rajagopalan K, Piercy J, Anderson P. Social and economic burden of walking and mobility problems in multiple sclerosis. BMC Neurol. 2012;12(1):94.

2. Dehghani A, Keshavarzi A. Development and validation of a multidimensional health literacy questionnaire for multiple sclerosis patients. Mult Scler Relat Disord. 2018;25:156-62.

3. Hosseinzadeh A, Baneshi MR, Sedighi B, Kermanchi J, Haghdoost AA. Incidence of multiple sclerosis in Iran: a nationwide, population-based study. Public Health. 2019;175:138-44.

4. Dehghani A, Khoramkish M, Isfahani SS. Challenges in the Daily Living Activities of Patients with Multiple Sclerosis: A Qualitative Content Analysis. Int J Community Based Nurs Midwifery. 2019;7(3):201.

5. Adamopoulou F, Alikari V, Zyga S, Tsironi M, Tzavella F, Giannakopoulou $\mathrm{N}$, et al. The Effect of Fatigue and Pain Self-Efficacy on Health-Related Quality of Life among Patients with Multiple Sclerosis. Mater Soc. 2019;31(1):40.

6. Stadelmann C. Multiple sclerosis as a neurodegenerative disease: pathology, mechanisms and therapeutic implications. Curr Opin Neurol. 2011;24:224-9.

7. Dehghani A, Nayeri ND, Ebadi A. Antecedents of coping with the disease in patients with multiple sclerosis: a qualitative content analysis. Int J Community Based Nurs Midwifery. 2017;5(1):49.

8. Ghandehari K, Riasi HR, Nourian A, Boroumand AR. Prevalence of multiple sclerosis in north east of Iran. Mult Scler J. 2010;16(12):1525.

9. Nicholl CR, Lincoln NB, Francis VM, Stephan TF. Assessment of emotional problems in people with multiple sclerosis. Clin Rehabil. 2001;15(6):657-68.

10. Nortvedt MW, Riise T, Frugaård J, Mohn J, Bakke A, Skår AB, et al. Prevalence of bladder, bowel and sexual problems among multiple sclerosis patients two to five years after diagnosis. Mult Scler J. 2007;13(1):106-12.

11. Dobryakova E, Genova HM, DeLuca J, Wylie GR. The dopamine imbalance hypothesis of fatigue in multiple sclerosis and other neurological disorders. Front Neurol. 2015;6:52.

12. Forbes A, While A, Mathes L, Griffiths P. Health problems and healthrelated quality of life in people with multiple sclerosis. Clin Rehabil. 2006;20(1):67-78.

13. Gjersing L, Caplehorn JR, Clausen T. Cross-cultural adaptation of research instruments: language, setting, time and statistical considerations. BMC Med Res Methodol. 2010;10(1):13. 
14. Haag DG, Peres KG, Balasubramanian M, Brennan DS. Oral conditions and health-related quality of life: a systematic review. J Dent Res. 2017:96(8):864-74.

15. Brennan DS. Oral health impact profile, EuroQol, and assessment of quality of life instruments as quality of life and health-utility measures of oral health. Eur J Oral Sci. 2013;121(3):188-93.

16. Turpin KV, Carroll LJ, Cassidy JD, Hader WJ. Deterioration in the healthrelated quality of life of persons with multiple sclerosis: the possible warning signs. Mult Scler. 2007;13(8):1038-45.

17. Goldberg DP, Gater R, Sartorius N, Ustun TB, Piccinelli M, Gureje O, et al. The validity of two version of the GHQ in the WHO study of mental illness in general health care. Psychol Med. 1997;27(1):191-7.

18. Sharrack B, Hughes RA. The Guy's neurological disability scale (GNDS): a new disability measure for multiple sclerosis. Mult Scler. 1999;5:223-33.

19. LoBiondo-Wood G, Haber J. Nursing research-E-book: methods and critical appraisal for evidence-based practice. Mosby; 9th edition; 2017.

20. Valizadeh $L$, Zamanzadeh $V$, Habibzadeh $H$, et al. Experiences of Iranian nurses that intent to leave the clinical nursing: a content analysis. J Caring Sci. 2016;5:169-78.

21. Graneheim UH, Lundman B. Qualitative content analysis in nursing research: concepts, procedures and measures to achieve trustworthiness. Nurse Educ Today. 2004;24:105-12.

22. Lacasse Y, Godbout C, Series F. Health-related quality of life in obstructive sleep apnoea. Eur Respir J. 2002;19(3):499-503.

23. Souza AC, Alexandre NM, Guirardello ED. Psychometric properties in instruments evaluation of reliability and validity. Epidemiol Serv Saúde. 2017;26:649-59.

24. Lawshe CH. A quantitative approach to content validity 1. Pers Psychol. 1975;28(4):563-75.

25. Ayre C, Scally AJ. Critical values for Lawshe's content validity ratio: revisiting the original methods of calculation. Meas Eval Couns Dev. 2014;47(1):79-86.

26. Polit DF, Beck CT, Owen SV. Is the CVI an acceptable indicator of content validity? Appraisal and recommendations. Res Nurs Health. 2007;30(4):459-67.

27. Hyrkäs K, Appelqvist-Schmidlechner K, Oksa L. Validating an instrument for clinical supervision using an expert panel. Int J Nurs Stud. 2003;40(6):619-25.

28. Rubio DM, Berg-Weger M, Tebb SS, Lee ES, Rauch S. Objectifying content validity: Conducting a content validity study in social work research. Soc Work Res. 2003;27(2):94-104.

29. Munro BH. Statistical methods for health care research: Lippincott Williams \& Wilkins; 5th edition 2005.

30. Hayton JC, Allen DG, Scarpello V. Factor retention decisions in exploratory factor analysis: A tutorial on parallel analysis. Organ Res Methods. 2004;7(2):191-205.

31. Patrick DL, Edwards TC, Topolski TD. Adolescent quality of life, part II: initial validation of a new instrument. J Adolesc. 2002;25(3):287-300.

32. Robins RJ, Zhang Y, Anderson MB, Presson AP, Burks RT, Greis PE. Convergent validity of the Patient Reported Outcomes Measurement
Information System's (PROMIS) Physical Function Computerized Adaptive Test (PF-CAT) for the knee and shoulder injury sports medicine patient population. Orthop J Sports Med. 2015;3(2 suppl):2325967115S00147.

33. Krishna H, Kumar K. Reliability estimation in generalized inverted exponential distribution with progressively type II censored sample. J Stat Comput Simul. 2013;83(6):1007-19.

34. Burns N, Grove SK. Using statistics to examine relationships. In: Burns N, Grove SK, editors. The Practice of nursing research: Conduct, Critique and Utilization. 5th ed. St Louis: Elsevier; 2005. p. 486-700.

35. De Boer MR, Moll AC, De Vet HC, Terwee CB, Völker-Dieben HJ, Van Rens $\mathrm{GH}$. Psychometric properties of vision-related quality of life questionnaires: a systematic review. Ophthalmic Physiol Opt. 2004;24(4):257-73.

36. Simeoni MC, Auquier P, Fernandez O, Flachenecker P, Stecchi S, Constantinescu CS, et al. Validation of the multiple sclerosis international quality of life questionnaire. Mult Scler J. 2008;14(2):219-30.

37. Wilski M, Tasiemski T. Illness perception, treatment beliefs, self-esteem, and self-efficacy as correlates of self-management in multiple sclerosis. Acta Neurol Scand. 2016;133(5):338-45.

38. Rooney S, McFadyen A, Wood L, Moffat F, Paul L. Minimally important difference of the fatigue severity scale and modified fatigue impact scale in people with multiple sclerosis. Mult Scler Relat Disord. 2019;35:158-63.

39. Al-Hussain F, Al-Salloum N, Alazwary N, Saeedi J, Howaidi S, Daif A. Depression, anxiety and stress severities in multiple sclerosis patients using injectable versus oral treatments. J Comp Eff Res. 2017;6(5):405-12.

40. Sadeghi Bahmani D, Esmaeili L, Shaygannejad V, Gerber M, Kesselring J, Lang UE, et al. Stability of mental toughness, sleep disturbances, and physical activity in patients with multiple sclerosis (MS) — a longitudinal and pilot study. Front Psychiatry. 2018:9:182.

41. Gullo HL, Fleming J, Bennett S, Shum DH. Cognitive and physical fatigue are associated with distinct problems in daily functioning, role fulfilment, and quality of life in multiple sclerosis. Mult Scler Relat Disord. 2019;31:118-23.

42. Gay MC, Bungener C, Thomas S, Vrignaud P, Thomas PW, Baker R, et al. Anxiety, emotional processing and depression in people with multiple sclerosis. BMC Neurol. 2017;17(1):43.

43. Phillips LH, Henry JD, Nouzova E, Cooper C, Radlak B, Summers F. Difficulties with emotion regulation in multiple sclerosis: Links to executive function, mood, and quality of life. J Clin Exp Neuropsychol. 2014;36(8):831-42.

44. Dehghani A, Kermanshahi SM, Memarian R, Karimirad MR. Depression and associated demographic factors' correlation in Multiple Sclerosis patients. Jundishapur J Chronic Dis Care. 2013;2(2):48-55.

\section{Publisher's Note}

Springer Nature remains neutral with regard to jurisdictional claims in published maps and institutional affiliations.

Ready to submit your research? Choose BMC and benefit from:

- fast, convenient online submission

- thorough peer review by experienced researchers in your field

- rapid publication on acceptance

- support for research data, including large and complex data types

- gold Open Access which fosters wider collaboration and increased citations

- maximum visibility for your research: over $100 \mathrm{M}$ website views per year

At BMC, research is always in progress.

Learn more biomedcentral.com/submissions 